\title{
Synthesis and Characterization of Novel Polymers Containing Sulfur from 3-Mercaptopropionic Acid
}

\author{
Yong-Kyung LeE, Kenjiro ONIMURA, Hiromori Tsutsumi, and Tsutomu OISHI ${ }^{\dagger}$ \\ Department of Applied Chemistry and Chemical Engineering, Faculty of Engineering, \\ Yamaguchi University, 2-16-1 Tokiwadai, Ube, Yamaguchi, 755-8611 Japan
}

(Received September 30, 1999)

\begin{abstract}
Three new monomers, 2-hydroxyethoxycarbonylethyl methoxycarbonylethyl sulfide (HEMS), 2hydroxyethoxycarbonyl (2'-methyl) ethyl methoxycarbonylethyl sulfide (HMMS), and 3,3'-dithiodiethylcarboxy allyl (DTCA) were synthesized from 3-mercaptopropionic acid (3-MPA) or methyl 3-mercaptopropionate (M3-MP). Polycondensations of HEMS and HMMS were performed with several metal acetates as catalysts to obtain the corresponding polythioethers with number average molecular weights $\left(M_{n}\right)$ of up to $6.4 \times 10^{3}$. Radical polymerizations of DTCA were carried out in bulk at $110^{\circ} \mathrm{C}$ to obtain polymers having allyl groups in the side chain. Polymerizations of DTCA with ethylene diamine (EDA) or hexamethylene diamine (HDA) were performed under various conditions to obtain the corresponding polymers. Decomposition temperatures $\left(T_{\mathrm{d}}\right)$ and glass transition temperatures $\left(T_{\mathrm{g}}\right)$ of the polymers were $146-$ $252^{\circ} \mathrm{C}$ and $-54--1^{\circ} \mathrm{C}$, respectively. Crystallinity of the polymers obtained by polymerizations of DTCA with EDA and HDA was $25-49 \%$.

KEY WORDS Polycondensation / 3-Mercaptopropionic Acid / Thioether / Disulfide / Glass Transition Temperature/ Degree of Crystallinity /
\end{abstract}

Many reports have appeared on the synthesis of macromonomers using thiols such as 3-mercaptopropionic acid (3-MPA). ${ }^{1-3}$ Star-shaped polymers containing sulfur were prepared by radical polymerizations of macromonomers, and properties for paints were studied. ${ }^{4,5}$ Mercapto-modified polymers were highly adsorptive toward heavy metal ions ${ }^{6}$ and useful for chain transfer agents of the radical polymerization to synthesize graft copolymers. ${ }^{7}$ The substituted allylic sulfides obtained from thiols as chain transfer agents in the radical polymerization gave end-functional polymers of controlled molecular weights. ${ }^{8}$ From this point of view, thiols such as 3-MPA are very often utilized for polymerization retarders and regulators in the field of macromolecules.

The objective of our studies was to search for effective and wide applications of thiols such as 3-MPA, except for application in polymerization retarder and regulator. We previously reported the synthesis and characterization of the polymers containing sulfur in the main and side chain using 3 -MPA. ${ }^{9,10}$

This paper describes the synthesis and polymerization of novel monomers, 2-hydroxyethoxycarbonylethyl methoxycarbonylethyl sulfide (HEMS), 2-hydroxyethoxycarbonyl (2'-methyl) ethyl methoxycarbonylethyl sulfide (HMMS) and 3,3'-dithiodiethylcarboxy allyl (DTCA), which have a sulfide or disulfide group. Characterizations of the polymers were made by thermal and Xray diffraction analyses, and NMR spectra.

\section{EXPERIMENTAL}

\section{Materials}

3-MPA and methyl 3-mercaptopropionate (M3-MP) were supplied by Nippon Oil \& Fats Co., Ltd. 3-MPA, M 3-MP, 2-hydroxyethyl acrylate (HEA), and 2-hydroxyethyl methacrylate (HEMA) were used after distilla-

\footnotetext{
${ }^{\dagger}$ To whom all correspondence should be addressed.
}

tion under reduced pressure. Allyl alcohol, ethylene diamine (EDA), and hexamethylene diamine (HDA) were used after distillation. Tetrahydrofuran (THF) and toluene were dried over sodium metal and then used after distillation. 2,2'-Azobisisobutyronitrle (AIBN) was purified by recrystallization from methanol. Other reagents were used without further purification. Monomers of HEMS, HMMS, and DTCA were synthesized, as drawn in Scheme 1.

HEMS. M3-MP $\left(6.0 \mathrm{~g}, 5.0 \times 10^{-2} \mathrm{~mol}\right)$ and an equimolar amount of HEA $\left(5.8 \mathrm{~g}, 5.0 \times 10^{-2} \mathrm{~mol}\right)$ were dissolved in THF $(50 \mathrm{~mL})$ in a Schlenk reaction tube. Tetrabutylammonium fluoride (TBAF) $\left(5.0 \times 10^{-4} \mathrm{~mol}\right)$ as catalyst was added to the solution, which was stirred at $25^{\circ} \mathrm{C}$ for $48 \mathrm{~h}$ under nitrogen atmosphere. The mixture was evaporated under reduced pressure and dissolved in suitable amount of ethyl acetate. The solution was washed with water and dried with anhydrous magnesium sulfate and filtered. The filtrate was evaporated under reduced pressure to give HEMS as a pale yellow oil. Further purification of HEMS was impossible because of the heat of oligomerization. HEMS may be used as a monomer, judging from ${ }^{1} \mathrm{H}$ and ${ }^{13} \mathrm{C}$ NMR spectra : yield $55 \% ;{ }^{1} \mathrm{H}$ NMR $[\delta$, ppm from tetramethylsilane (TMS) in $\left.\mathrm{CDCl}_{3}\right] 4.27-4.24\left(\mathrm{t}, \mathrm{J}=4.62,2 \mathrm{H},-\mathrm{CH}_{2} \mathrm{CH}_{2}\right.$ $\mathrm{OH}), 3.85-3.82\left(\mathrm{t}, \mathrm{J}=4.62,2 \mathrm{H},-\mathrm{CH}_{2} \mathrm{CH}_{2} \mathrm{OH}\right), 3.71(\mathrm{~s}$, $\left.3 \mathrm{H}, \mathrm{CH}_{3} \mathrm{OCO}^{-}\right), 2.86-2.80\left(\mathrm{~m}, 4 \mathrm{H},-\mathrm{CH}_{2} \mathrm{CH}_{2} \mathrm{SCH}_{2} \mathrm{CH}_{2}^{-}\right.$), 2.70-2.60 (m, 4H, $\left.-\mathrm{CH}_{2} \mathrm{CH}_{2} \mathrm{SCH}_{2} \mathrm{CH}_{2}-\right), 2.39$ (b, $1 \mathrm{H}$, $-\mathrm{OH}) ;{ }^{13} \mathrm{C} \mathrm{NMR}\left(\delta\right.$, ppm from TMS in $\left.\mathrm{CDCl}_{3}\right) 172.29(\mathrm{C}$ $=\mathrm{O}), 171.99(\mathrm{C}=\mathrm{O}), 66.23\left(-\mathrm{CH}_{2} \mathrm{CH}_{2} \mathrm{OH}\right), 60.97\left(-\mathrm{CH}_{2}\right.$ $\left.\mathrm{CH}_{2} \mathrm{OH}\right), 51.83\left(\mathrm{CH}_{3} \mathrm{OCO}^{-}\right), 34.59\left(\mathrm{CH}_{3} \mathrm{OCOCH}_{2} \mathrm{CH}_{2} \mathrm{~S}^{-}\right)$, $34.50 \quad\left(-\mathrm{SCH}_{2} \mathrm{CH}_{2} \mathrm{COOCH}_{2}-\right), 27.10 \quad\left(\mathrm{CH}_{3} \mathrm{OCOCH}_{2} \mathrm{CH}_{2}\right.$ $\mathrm{S}-), 26.92\left(-\mathrm{SCH}_{2} \mathrm{CH}_{2} \mathrm{COOCH}_{2}-\right)$.

HMMS. HMMS is a pale yellow oil that was synthesized from M3-MP and HEMA by the same procedure as the synthesis of HEMS : yield $73 \% ;{ }^{1} \mathrm{H}$ NMR $(\delta, \mathrm{ppm}$ from TMS in $\left.\mathrm{CDCl}_{3}\right) 4.28-4.10\left(\mathrm{~m}, 2 \mathrm{H},-\mathrm{CH}_{2} \mathrm{CH}_{2} \mathrm{OH}\right)$, $3.77-3.75$ (t, $\left.J=3.63,2 \mathrm{H},-\mathrm{CH}_{2} \mathrm{CH}_{2} \mathrm{OH}\right), 3.63(\mathrm{~s}, 3 \mathrm{H}$, 
(a)

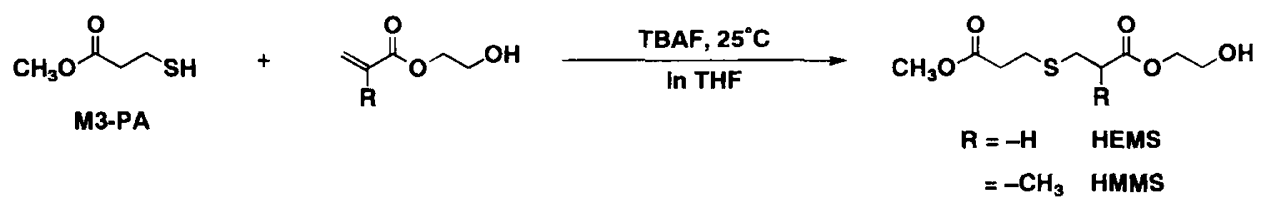

(b)<smiles>O=C(O)CCS</smiles>

3-MPA

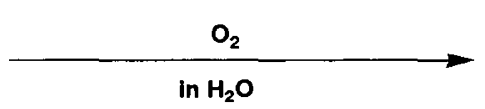

in $\mathrm{H}_{\mathbf{2}} \mathrm{O}$<smiles>O=C(O)CCCCCCCCSCCC(=O)O</smiles>

DTPA

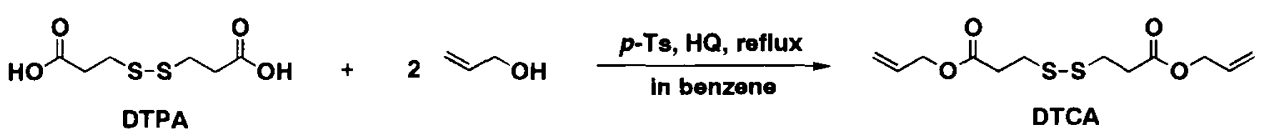

Scheme 1.

$\left.\mathrm{CH}_{3} \mathrm{OCO}-\right)$, 2.77-2.52 (m, $7 \mathrm{H},-\mathrm{CH}_{2} \mathrm{CH}_{2} \mathrm{SCH}\left(\mathrm{CH}_{3}\right)$ $\left.\mathrm{CH}_{2}-\right), 2.33(\mathrm{~b}, 1 \mathrm{H},-\mathrm{OH}), 1.21-1.19(\mathrm{~d}, J=6.60,3 \mathrm{H}$, $\left.-\mathrm{SCH}\left(\mathrm{CH}_{3}\right) \mathrm{CH}_{2}{ }^{-}\right) ;{ }^{13} \mathrm{C} \mathrm{NMR}$ ( $\delta$, ppm from TMS in $\left.\mathrm{CDCl}_{3}\right) 172.29(\mathrm{C}=\mathrm{O}), 66.24\left(-\mathrm{CH}_{2} \mathrm{CH}_{2} \mathrm{OH}\right), 60.99\left(-\mathrm{CH}_{2}\right.$ $\left.\mathrm{CH}_{2} \mathrm{OH}\right), 51.81\left(\mathrm{CH}_{3} \mathrm{OCO}-\right), 40.11\left(-\mathrm{SCH}\left(\mathrm{CH}_{3}\right) \mathrm{CH}_{2}-\right)$, $35.64\left(-\mathrm{SCH}\left(\mathrm{CH}_{3}\right) \mathrm{CH}_{2}-\right), 34.58\left(-\mathrm{OCOCH}_{2} \mathrm{CH}_{2} \mathrm{~S}^{-}\right), 27.37$ $\left(-\mathrm{OCOCH}_{2} \mathrm{CH}_{2} \mathrm{~S}^{-}\right), 16.84\left(-\mathrm{SCH}\left(\mathrm{CH}_{3}\right) \mathrm{CH}_{2}-\right)$.

3,3'-Dithiodipropionic Acid (DTPA). 3-MPA (2.2 g, $\left.2.0 \times 10^{-2} \mathrm{~mol}\right)$ was dissolved in distilled water $(40 \mathrm{~mL})$. The solution was stirred at $25^{\circ} \mathrm{C}$ for $72 \mathrm{~h}$ bubbling oxygen and filtered. The obtained product was washed with water and dried under vacuum to give DTPA as a white powder: yield $63 \%$; mp $156-158^{\circ} \mathrm{C} ;{ }^{1} \mathrm{H} \mathrm{NMR}(\delta$, in dimethyl sulfoxide (DMSO)- $d_{6}$ ) 12.37 (brs, $2 \mathrm{H},-\mathrm{COOH}$ ), $2.93-2.88\left(\mathrm{t}, J=6.93,4 \mathrm{H},-\mathrm{CH}_{2} \mathrm{CH}_{2} \mathrm{~S}^{-}\right), 2.67-2.62(\mathrm{t}, J$ $\left.=6.93,4 \mathrm{H},-\mathrm{CH}_{2} \mathrm{CH}_{2} \mathrm{~S}^{-}\right) ;{ }^{13} \mathrm{C}$ NMR $\left(\delta\right.$, in DMSO- $\left.d_{6}\right)$ $172.63(\mathrm{C}=\mathrm{O}), 33.57\left(-\mathrm{CH}_{2} \mathrm{CH}_{2} \mathrm{~S}^{-}\right), 33.03\left(-\mathrm{CH}_{2} \mathrm{CH}_{2} \mathrm{~S}^{-}\right)$.

DTCA. DTPA $\left(5.0 \mathrm{~g}, 2.4 \times 10^{-2} \mathrm{~mol}\right)$, allyl alcohol $\left(3.7 \mathrm{~g}, 6.4 \times 10^{-2} \mathrm{~mol}\right), p$-toluenesulfonic acid $(0.1 \mathrm{~g})$ and hydroquinone $(0.1 \mathrm{~g})$ were placed in benzene $(100 \mathrm{~mL})$. The solution was heated under reflux for $6 \mathrm{~h}$, cooled to room temperature and then washed with water. The solution was dried with anhydrous magnesium sulfate and evaporated under reduced pressure to give DTCA as a colorless oil : yield $90 \% ;{ }^{1} \mathrm{H}$ NMR ( $\delta$, ppm from TMS in $\left.\mathrm{CDCl}_{3}\right) 6.00-5.85\left(\mathrm{~m}, 2 \mathrm{H}, \mathrm{CH}_{2}=\mathrm{CH}^{-}\right), 5.37-5.22(\mathrm{~m}, 4$ $\left.\mathrm{H}, \mathrm{CH}_{2}=\mathrm{CH}^{-}\right), 4.62-4.59\left(\mathrm{~m}, 4 \mathrm{H},-\mathrm{CH}_{2} \mathrm{OCO}^{-}\right), 2.97-$ $2.91\left(\mathrm{~m}, 4 \mathrm{H},-\mathrm{CH}_{2} \mathrm{CH}_{2} \mathrm{~S}^{-}\right), 2.80-2.74\left(\mathrm{~m}, 4 \mathrm{H},-\mathrm{CH}_{2} \mathrm{CH}_{2}\right.$ $\left.\mathrm{S}^{-}\right) ;{ }^{13} \mathrm{C}$ NMR ( $\delta$, ppm from TMS in $\left.\mathrm{CDCl}_{3}\right) 171.28(\mathrm{C}=$ O), $131.91\left(\mathrm{CH}_{2}=\mathrm{CH}-\right), 118.49\left(\mathrm{CH}_{2}=\mathrm{CH}^{-}\right), 65.45\left(-\mathrm{CH}_{2}\right.$ OCO-), $34.02\left({ }^{-} \mathrm{CH}_{2} \mathrm{CH}_{2} \mathrm{~S}^{-}\right), 33.05\left(-\mathrm{CH}_{2} \mathrm{CH}_{2} \mathrm{~S}^{-}\right)$.

\section{Polycondensations of HEMS and HMMS}

HEMS (or HMMS) and metal acetate were placed in a round-bottomed flask fitted with a magnetic stirrer. Polycondensations were performed in three steps: the mixture was heated $180^{\circ} \mathrm{C}$ for $3 \mathrm{~h}$, the system was subjected to reduced pressure of approximately $30 \mathrm{mmHg}$ for $3 \mathrm{~h}$, and then vacuum of approximately $0.1 \mathrm{mmHg}$ for $3 \mathrm{~h}$. After cooling to room temperature, the polymer was dissolved in $\mathrm{CHCl}_{3}$. The polymer solution was washed with water, evaporated under reduced pressure, and precipitated by an addition of methanol. The obtained polymer was purified by reprecipitating it twice from the $\mathrm{CHCl}_{3}$ solution to excess methanol. The polymer was decanted and dried under vacuum for 3 days.

\section{Radical Polymerization of DTCA}

Radical polymerizations were performed with AIBN and di-t-butylperoxide (DTBP) as initiator in a sealed tube at $60^{\circ} \mathrm{C}$ and $110^{\circ} \mathrm{C}$ under nitrogen atmosphere. After polymerization, the polymer solution was poured into a large amount of methanol to precipitate the polymer. The polymer was purified by reprecipitating it twice from the THF solution to excess methanol. The polymer was decanted and dried under vacuum for 3 days.

\section{Polymerizations of DTCA with Diamine}

Polymerizations of DTCA with EDA (or HDA) were carried out in a sealed tube or three-neck flask fitted with a magnetic stirrer at $60^{\circ} \mathrm{C}$ and $120^{\circ} \mathrm{C}$ under nitrogen atmosphere. After polymerization, the mixture was poured into excess methanol to precipitate the polymer. The polymer was decanted and dried under vacuum for 3 days.

\section{Measurements}

NMR spectra were recorded at $25^{\circ} \mathrm{C}$ using JEOL EX270 (Jeol Ltd.). Gel permeation chromatography (GPC) measurements were carried out at $50^{\circ} \mathrm{C}$ on a Shimadzu SPD-10A (Shimadzu Ltd.) equipped with a UV detector and HSG-40, HSG-20, HSG-15, and HSG-10 columns using THF as an eluent. Thermal stability was measured by a differential scanning calorimeter with a SSC/5200 (Seiko Ltd.) and Shimadzu DSC-50. X-Ray diffraction analysis was carried out with a Shimadzu XD-D1.

\section{RESULTS AND DISCUSSION}

\section{Polycondensations of HEMS and HMMS}

The results of the polycondensations of HEMS and HMMS are summarized in Table I. Polycondensations were performed in the presence of several metal acetates used in previous work, ${ }^{9}$ and proceeded heterogeneously throughout. The resulting polymers were pale yellow rubbery and soluble in ordinary polar solvents such as 
Table I. Polycondensation of HEMS and HMMS ${ }^{\text {a }}$

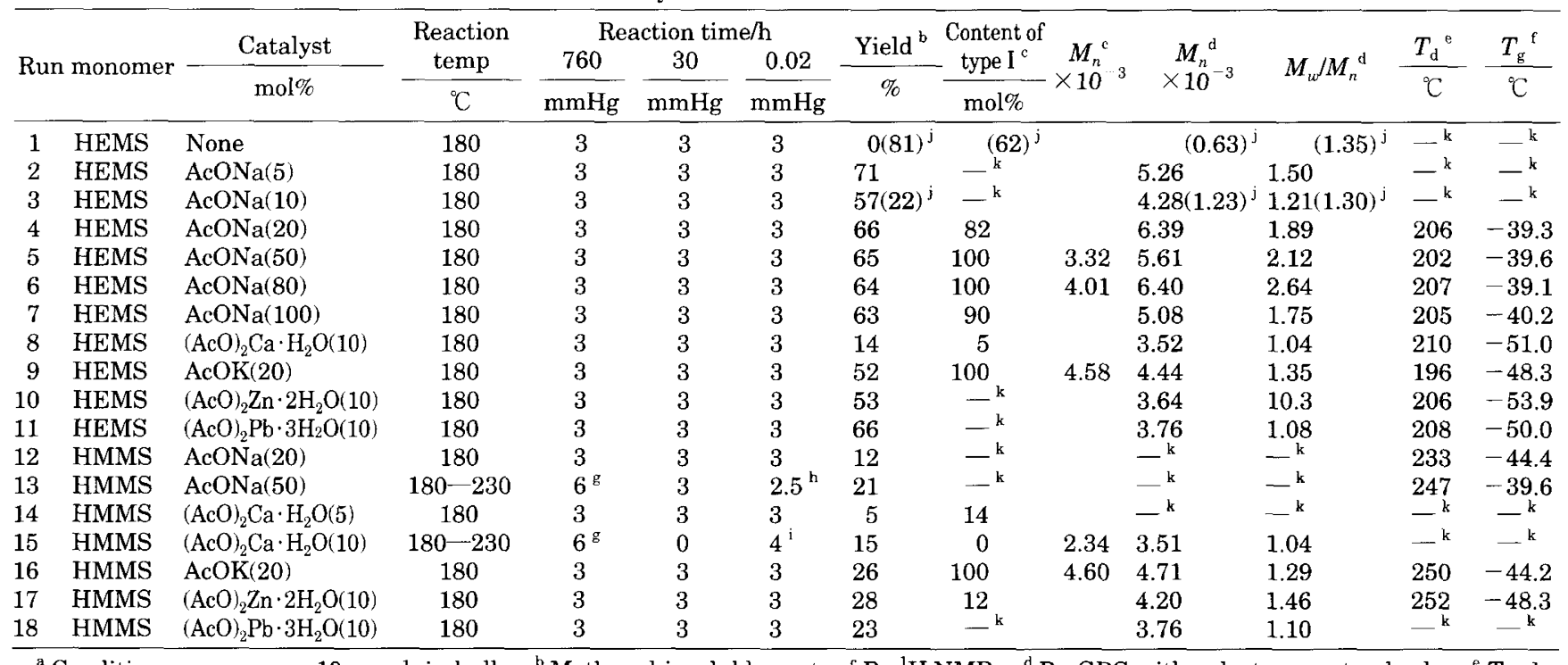

${ }^{\mathrm{a}}$ Conditions; monomer $=10 \mathrm{mmol}$, in bulk. ${ }^{\mathrm{b}}$ Methanol-insoluble part. ${ }^{\mathrm{c}} \mathrm{By}{ }^{1} \mathrm{H} \mathrm{NMR}$. ${ }^{\mathrm{d}} \mathrm{By}$ GPC with polystyrene standards. ${ }^{\mathrm{e}} T_{\mathrm{d}}$, decomposition temperature by TG. ${ }^{\mathrm{f}} T_{\text {g }}$, glass transition temperature by DSC. ${ }^{\mathrm{g}}$ Under nitrogen at $180^{\circ} \mathrm{C}$. ${ }^{\mathrm{h}} 1 \mathrm{~h}$ at $180^{\circ} \mathrm{C}$ and $1.5 \mathrm{~h}$ at $230^{\circ} \mathrm{C}$. ${ }^{\mathrm{i}} 1 \mathrm{~h}$ at $180^{\circ} \mathrm{C}$ and $3 \mathrm{~h}$ at $230^{\circ} \mathrm{C}$. ${ }^{\mathrm{j}}$ Methanol-soluble and $n$-hexane-insoluble part. ${ }^{\mathrm{k}}$ Not determined.

chloroform and THF.

${ }^{1} \mathrm{H}$ NMR spectra of HMMS and poly(HMMS)s are shown in Figure 1. Some peaks assigned to methylene protons (Figures 1(1), 7, and 8) of HMMS at $4.28-4.10$ ppm and $3.77-3.75 \mathrm{ppm}$ sifted to one peak (Figures $1(2), 7$, and 8) at $4.25 \mathrm{ppm}$ after polycondensation. In Figure 1(3) a peak assigned to end methylene at 3.77$3.75 \mathrm{ppm}$ was clearly observed but does not appear in Figure 1(2). These results suggest that the obtained polymers by the polycondensation of HRMS could have two structures (types I and II in Scheme 2). The use of $\mathrm{AcONa}$ and $\mathrm{AcOK}$ as catalysts gave more type I than type II polymer, but the use of $(\mathrm{AcO})_{2} \mathrm{Ca} \cdot \mathrm{H}_{2} \mathrm{O}$ and $(\mathrm{AcO})_{2}$ $\mathrm{Zn} \cdot 2 \mathrm{H}_{2} \mathrm{O}$ gave more type II than type I polymer (Table I). It is difficult to clearly explain the reason, but the kinds of metals and hydrate moiety may play important roles. Especially poly(HMMS) (run 15) exhibited only type II, as shown in Figure 1(2), because of high polycondensation temperature at $230^{\circ} \mathrm{C}$.

Yields of poly(HMMS) were lower than those of poly(HEMS) owing to steric hindrance $\alpha$-methyl groups for HMMS. Figure 2 shows relationships between metal acetate amounts and yields, and $M_{n}$ determined by GPC for poly(HEMS). AcONa and $(\mathrm{AcO})_{2} \mathrm{~Pb} \cdot 3 \mathrm{H}_{2} \mathrm{O}$ as catalysts gave the highest polymer yield. But with $(\mathrm{AcO})_{2} \mathrm{~Pb}$. $3 \mathrm{H}_{2} \mathrm{O}$ as catalyst, byproducts such as $\mathrm{PbS}$ were formed in the polycondensation of compounds having a sulfide such as 3-hydroxypropyl methoxycarbonylethyl sulfide (HPMES). ${ }^{9}$ Amounts of metal acetate scarcely influenced yields of methanol-insoluble polymers though the absence of metal acetate gave no methanol-insoluble polymers but $n$-hexane-insoluble oligomers (run 1; $M_{n}$ $=6.3 \times 10^{2}, M_{w} / M_{n}=1.3$ ). The polycondensations of HPMES also could not proceed without metal acetate. ${ }^{9}$

$M_{n}$ of poly(HEMS) obtained with AcONa exhibited relatively high value and was little influenced by the amount of catalyst, and $M_{w} / M_{n}$ was nearly $2 . M_{w} / M_{n}$ of polymers obtained by polycondensation is nearly $2{ }^{11}$ With $(\mathrm{AcO})_{2} \mathrm{Ca} \cdot \mathrm{H}_{2} \mathrm{O},(\mathrm{AcO})_{2} \mathrm{Zn} \cdot 2 \mathrm{H}_{2} \mathrm{O}$ and $(\mathrm{AcO})_{2} \mathrm{~Pb}$.
(1)

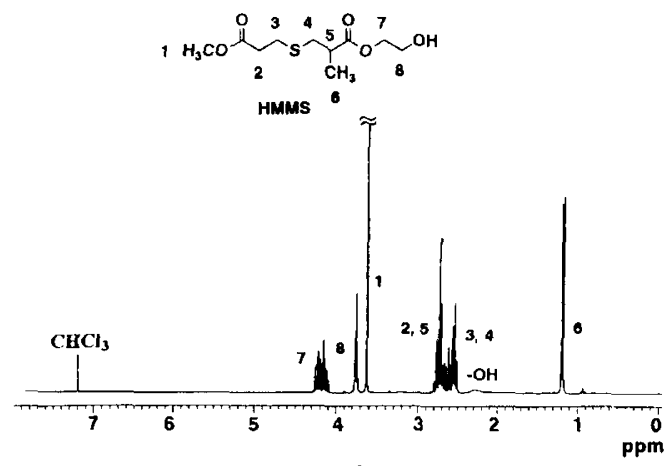

(2)
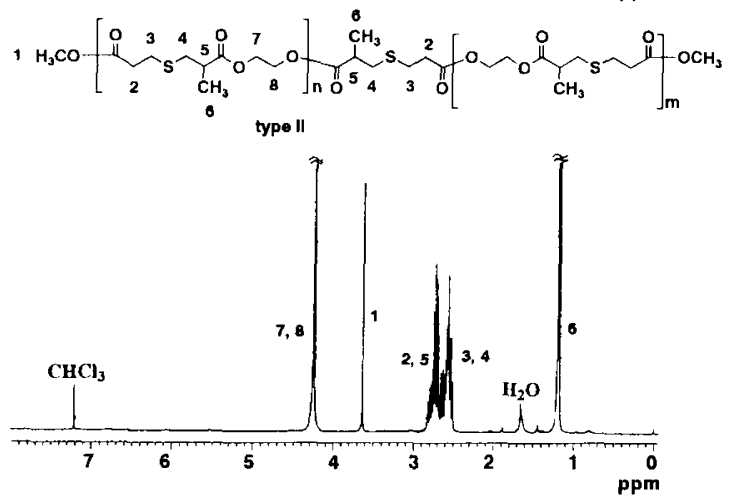

(3)

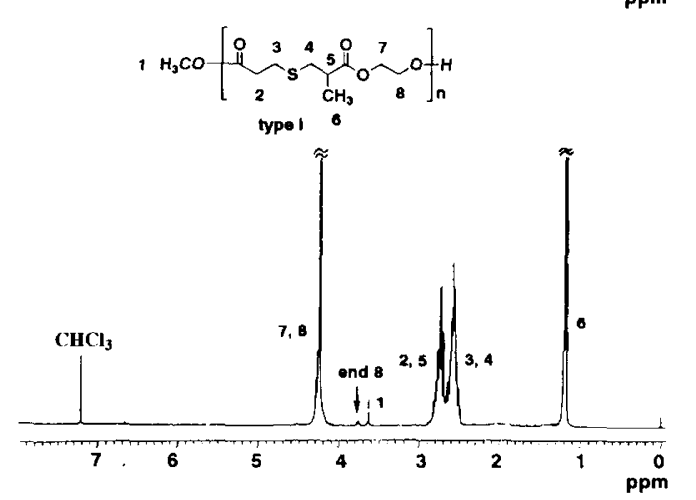

Figure 1. ${ }^{1} \mathrm{H}$ NMR spectra for $\mathrm{HMMS}$ and poly(HMMS) in $\mathrm{CDCl}_{3}$ at $23.5^{\circ} \mathrm{C}(270 \mathrm{MHz})$; (1) HMMS, (2) run 15 , and (3) run 16 in Table I. 

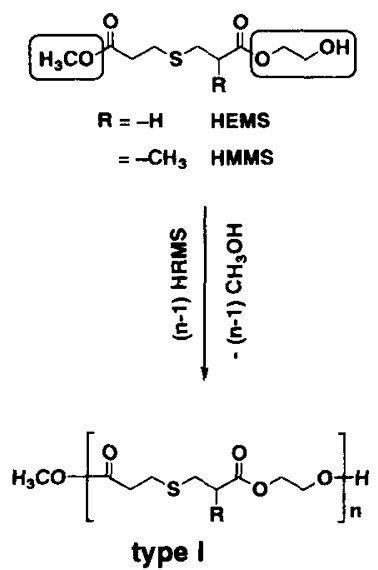

type I
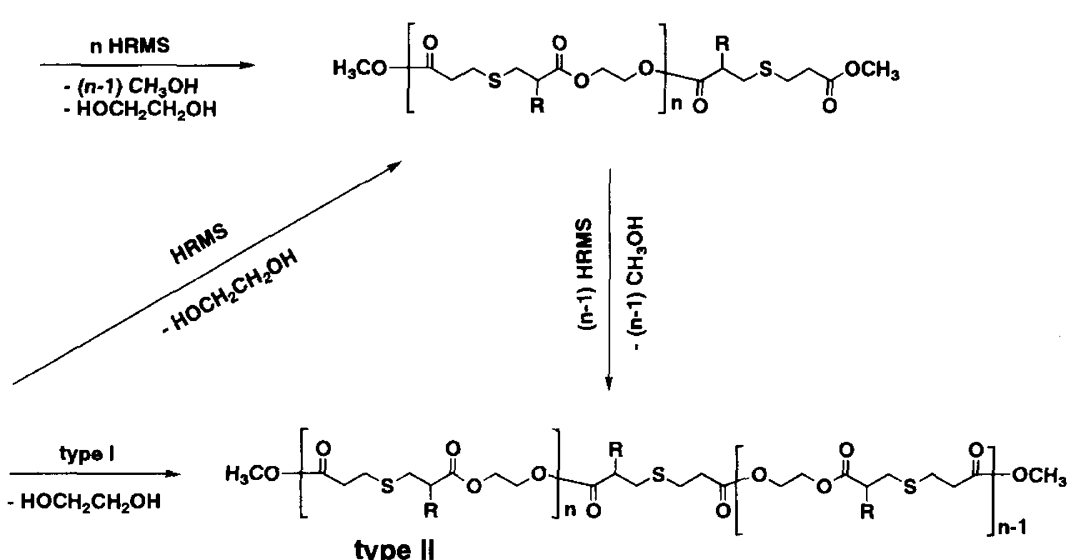

Scheme 2.
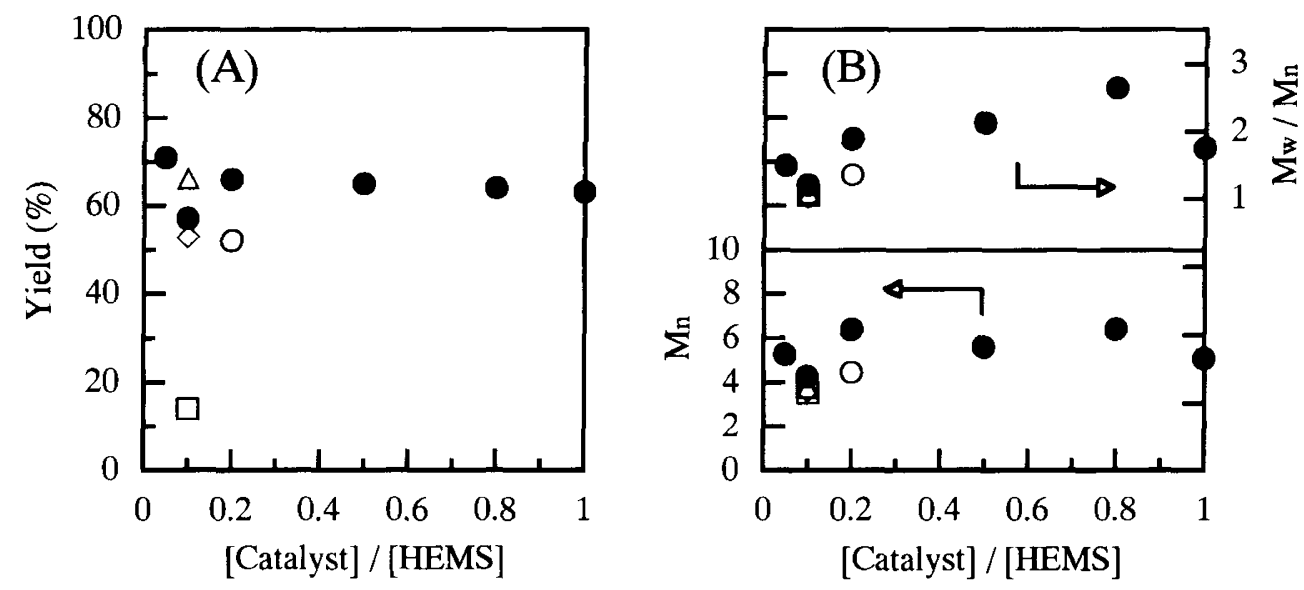

Figure 2. Relationships between amount of catalyst and (A) yield (\%), and (B) $M_{n}$ of poly $(\mathrm{HEMS})$; $\mathrm{H}_{2} \mathrm{O},(\diamond)(\mathrm{AcO})_{2} \mathrm{Zn} \cdot 2 \mathrm{H}_{2} \mathrm{O}$, and $(\triangle)(\mathrm{AcO})_{2} \mathrm{~Pb} \cdot 3 \mathrm{H}_{2} \mathrm{O}$.

Table II. Redical polymerization of DTCA

\begin{tabular}{|c|c|c|c|c|c|c|c|c|}
\hline \multirow{2}{*}{ Run } & \multirow{2}{*}{$\frac{\mathrm{DTCA}}{\mathrm{mmol}}$} & \multirow{2}{*}{$\frac{\text { Initiator }^{a}}{\text { mol\% }}$} & \multirow{2}{*}{$\frac{\text { Solvent }}{\mathrm{mL}}$} & \multirow{2}{*}{$\begin{array}{c}\text { Polym. } \\
\text { temp }\end{array}$} & \multirow{2}{*}{$\begin{array}{c}\begin{array}{c}\text { Polym. } \\
\text { time }\end{array} \\
\mathrm{h}\end{array}$} & \multirow{2}{*}{$\frac{\text { Yield }^{b}}{\%}$} & \multirow{2}{*}{$\begin{aligned} & M_{n}^{\mathrm{c}} \\
& \times 10^{-3}\end{aligned}$} & \multirow{2}{*}{$M_{w} / M_{n}^{\mathrm{c}}$} \\
\hline & & & & & & & & \\
\hline 1 & 1.7 & $\operatorname{AIBN}(1)$ & THF(1) & 60 & 24 & Trace & & \\
\hline 2 & 1.7 & $\operatorname{AIBN}(5)$ & THF(1) & 60 & 24 & Trace & & \\
\hline 3 & 1.7 & $\operatorname{AIBN}(10)$ & THF (1) & 60 & 24 & Trace & & \\
\hline 4 & 1.7 & DTBP(5) & None & 110 & 24 & 4.1 & 2.3 & 1.67 \\
\hline 5 & 1.7 & $\operatorname{DTBP}(10)$ & None & 110 & 24 & 8.7 & 2.7 & 1.46 \\
\hline
\end{tabular}

${ }^{a}$ AIBN, 2, 2'-azobisisobutyronitrile; DTBP, di-t-butylperoxide. ${ }^{b}$ Methanol-insoluble part. ${ }^{\mathrm{c}}$ By GPC with polystyrene standards.

$3 \mathrm{H}_{2} \mathrm{O}$ as catalyst, $M_{n}$ of poly(HEMS) was about $3.5 \times 10^{3}$ and $M_{w} / M_{n}$ was nearly 1 . The polymer having $M_{n}$ lower than about 3500 may thus be soluble in methanol of precipitant. In fact, we recovered the methanol-soluble part whose $M_{n}$ and $M_{w} / M_{n}$ were $1.2 \times 10^{3}$ and 1.3 , respectively (run 3).

\section{Radical Polymerization of DTCA}

The results of the radical polymerization of DTCA are summarized in Table II. The polymerization could not proceed with AIBN at $60^{\circ} \mathrm{C}$, but with DTBP at $110^{\circ} \mathrm{C}$ to give the polymer of a pale yellow oil. Yields and $M_{n}$ of the polymers were $4-9 \%$ and $2.3 \times 10^{3}-2.7 \times 10^{3}$, respectively, because of chain transfer by active hydrogen of allyl groups.

${ }^{1} \mathrm{H}$ NMR spectra of DTCA and poly(DTCA) are shown in Figure 3. The peaks assigned to the main chain at $1.05-2.70 \mathrm{ppm}$ and allyl group at $5.23-5.99 \mathrm{ppm}$ were clearly observed. The ratio of the integrated intensity of peaks assigned to methine proton at $5.85-6.00$ ppm and two ethylene groups neighboring a disulfide group at $2.75-2.97 \mathrm{ppm}$ was $1: 8$. Thus poly(DTCA) may have allyl groups in the side chain end without crosslinkage.

\section{Polyaddition of DTCA with Diamine}

The results of the polymerizations of DTCA with EDA and HDA are summarized in Table III. Polymerizations 

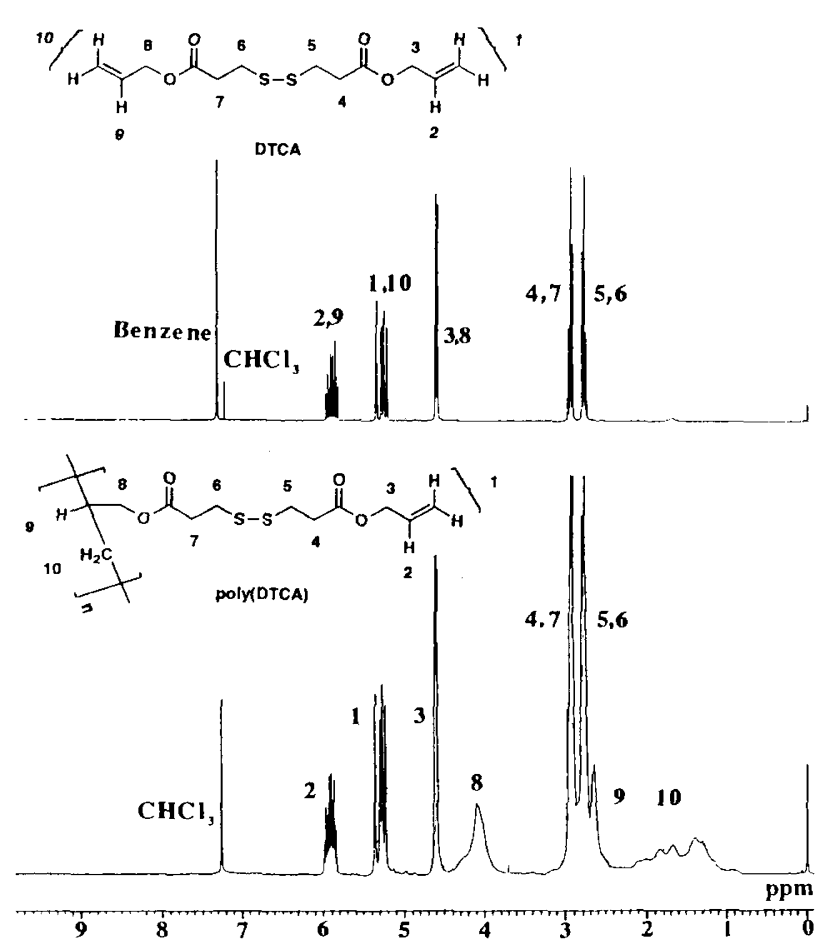

Figure 3. ${ }^{1} \mathrm{H}$ NMR spectra for DTCA and poly(DTCA) (run 5 in Table II $)$ in $\mathrm{CDCl}_{3}$ at $23.5^{\circ} \mathrm{C}(270 \mathrm{MHz})$.

(1)
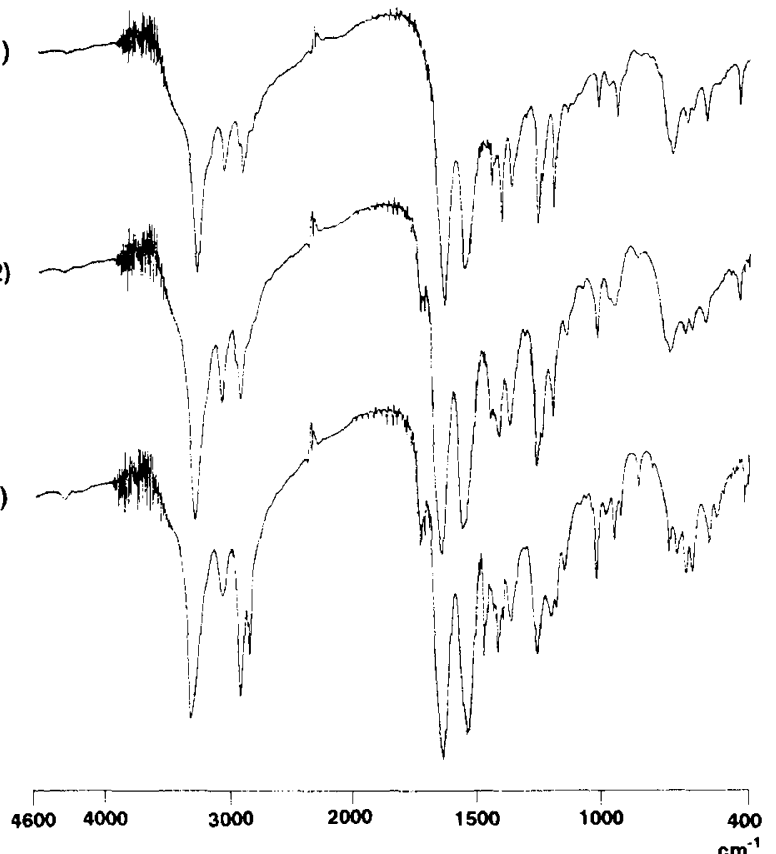

Figure 4. Infrared spectra for poly(DTCA-EDA) and poly(DTCAHDA) ; (1) run 3, (2) run 4 , and (3) run 6 in Table III.

were carried out in toluene and bulk at $60^{\circ} \mathrm{C}$ and $120^{\circ} \mathrm{C}$ to obtain the corresponding polymers of a pale yellow powder. The bulk polymerization without a catalyst gave the highest yield (run 5,6). All the polymers were insoluble in general organic solvents such as acetone, benzene, methanol, chloroform, THF, DMF, and DMSO but only soluble in trifluoroacetic acid.

Figure 4 shows infrared spectra of the poly(DTCA-

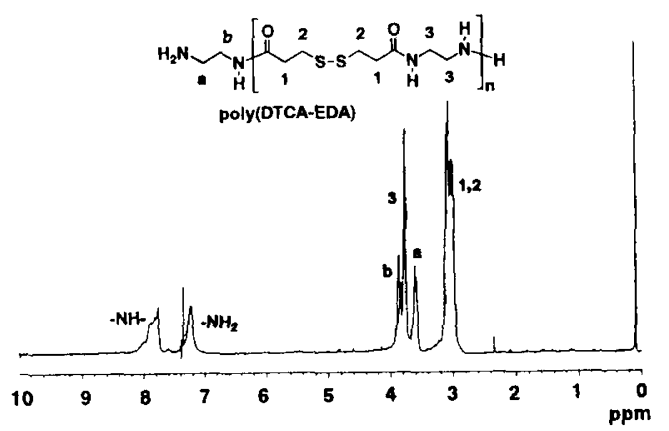

(2)

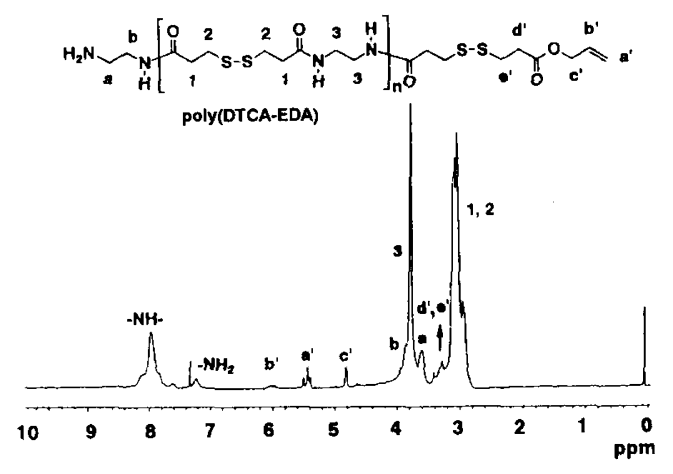

(3)

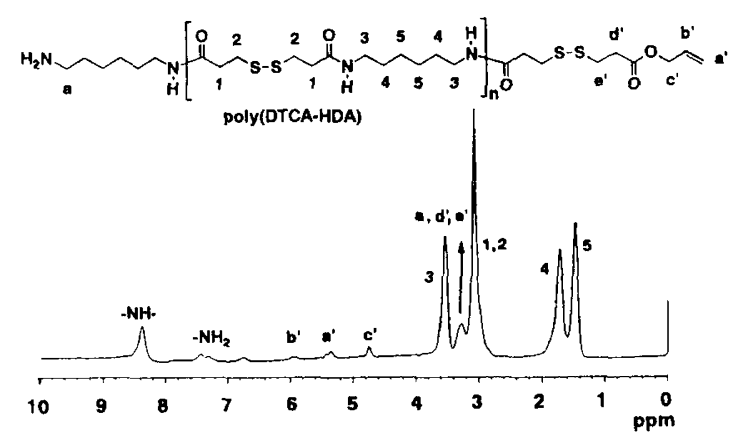

Figure 5. ${ }^{1} \mathrm{H}$ NMR spectra for poly(DTCA-EDA) and poly(DTCA$\mathrm{HDA})$ in trifluoroacetic acid/CDCl $\left(6 / 4_{\text {volume }}\right)$ at $23.5^{\circ} \mathrm{C}(270 \mathrm{MHz})$; (1) run $3,(2)$ run 4 , and (3) run 6 in Table III.

EDA) and poly(DTCA-HDA). Strong absorption due to amide groups was clearly observed at $1640 \mathrm{~cm}^{-1}$ and $1550 \mathrm{~cm}^{-1}$ for all the polymers. Absorption due to ester groups at $1720 \mathrm{~cm}^{-1}$ was very weakly or not observed. From these results the poly(DTCA-EDA) and poly(DTCA-HDA) may have linear structures by the condensation of DTCA with EDA and HDA, as shown in Figure 5 . Insolubility of the polymers in several solvents could be attributed to the rigid amide groups. $M_{n}$ s of the poly(DTCA-RDA)s determined by ${ }^{1} \mathrm{H}$ NMR spectra were 6.0 $\times 10^{2}-2.1 \times 10^{3}$.

\section{Characterization}

Glass transition temperatures $\left(T_{\mathrm{g}}\right)$ and decomposition temperatures $\left(T_{\mathrm{d}}\right)$ of poly(HRMS)s were $-39--54^{\circ} \mathrm{C}$ and $196-252^{\circ} \mathrm{C}$, respectively, as shown in Table I. The low $T_{\mathrm{g}}$ is attributed to the sulfur atom in the main chain. Figure 6 exhibits relationships between $M_{n}$ and $T_{g}$, and $T_{\mathrm{d}}$ of poly(HRMS)s. The $T_{\mathrm{g}}$ of the poly(HRMS)s increased with the $M_{n}$ under $5.0 \times 10^{3}$ but $T_{\mathrm{d}}$ of the poly(HRMS)s did not depend on the $M_{n} . T_{\mathrm{g}}$ of poly(HMMS) was similar to that of poly(HEMS) but $T_{\mathrm{d}}$ of poly(HMMS) was higher than that of poly(HEMS). $T_{\mathrm{g}}$ is thus affected by $\alpha$-methyl group but $T_{\mathrm{d}}$ could not be affected. 
Y-K. LEE et al.

Table III. Polymerization of DTCA with Diamine ${ }^{a}$

\begin{tabular}{|c|c|c|c|c|c|c|c|c|c|c|}
\hline \multirow[t]{2}{*}{ Run } & \multirow[t]{2}{*}{ Diamine } & \multirow{2}{*}{$\frac{\text { Catalyst }^{\mathrm{b}}}{\mathrm{mol} \%}$} & \multirow{2}{*}{$\frac{\begin{array}{c}\text { Polym. } \\
\text { solvent }^{\mathrm{c}}\end{array}}{\mathrm{mL}}$} & \multirow{2}{*}{$\begin{array}{c}\text { Polym. } \\
\text { temp } \\
{ }^{\circ} \mathrm{C}\end{array}$} & \multirow{2}{*}{$\begin{array}{c}\text { Polym. } \\
\text { time }\end{array}$} & \multirow{2}{*}{$\frac{\text { Yield }^{\mathrm{d}}}{\%}$} & \multirow{2}{*}{$\begin{array}{c}M_{n}^{\mathrm{e}} \\
\times 10^{-3}\end{array}$} & \multirow{2}{*}{$\begin{array}{l}T_{\mathrm{d}}^{\mathrm{f}} \\
{ }^{\circ} \mathrm{C}\end{array}$} & \multirow{2}{*}{$\frac{T_{\mathrm{g}}^{\mathrm{g}}}{{ }^{\circ} \mathrm{C}}$} & \multirow{2}{*}{$\frac{\mathrm{X}^{\mathrm{h}}}{\%}$} \\
\hline & & & & & & & & & & \\
\hline 1 & EDA & None & Tol.(25) & 120 & 9 & Trace & & & & \\
\hline 2 & EDA & EtONa $(20)$ & Tol.(10) & 120 & 24 & Trace & & & & \\
\hline 3 & EDA & AIBN(10) & Tol.(1) & 60 & 24 & 32.3 & 0.60 & 146 & -1.0 & 49.3 \\
\hline 4 & EDA & $\operatorname{DTBP}(10)$ & None & 120 & 1 & 31.7 & 2.11 & 146 & -4.7 & 28.7 \\
\hline 5 & EDA & None & None & 60 & 30 & 49.7 & $-^{\mathrm{i}}$ & $-{ }^{\mathrm{i}}$ & $-i$ & $-i$ \\
\hline 6 & HDA & None & None & 60 & 30 & 50.9 & 1.85 & 182 & -3.2 & 25.0 \\
\hline 7 & HDA & AIBN(10) & Tol.(1) & 60 & 30 & 27.2 & 1.65 & 178 & -1.0 & 26.7 \\
\hline 8 & HDA & None & Tol.(1) & 60 & 30 & 26.6 & $-{ }^{i}$ & 176 & $-i$ & 27.1 \\
\hline
\end{tabular}

${ }^{\mathrm{a}} \mathrm{DTCA}=1.8 \mathrm{mmol}$; diamine $=1.8 \mathrm{mmol}$; EDA, ethylendiamine ; HDA, hexamethylendiamine. ${ }^{\mathrm{b}}$ EtONa, sodium ethoxide ; AIBN, 2,2 'azobisisobutyronitrile; DTBP, di-t-butylperoxide. ${ }^{c}$ Tol., Toluene. ${ }^{d}$ Methanol-insoluble part. ${ }^{e}$ By ${ }^{1} \mathrm{H}$ NMR. ${ }^{f} T_{\mathrm{d}}$, decomposition temperature by TG. ${ }^{\mathrm{g}} T_{\mathrm{g}}$, glass transition temperature by DSC. ${ }^{\mathrm{h}} \mathrm{X}$, crystallinity by XRD. ${ }^{\mathrm{i}}$ Not determined.
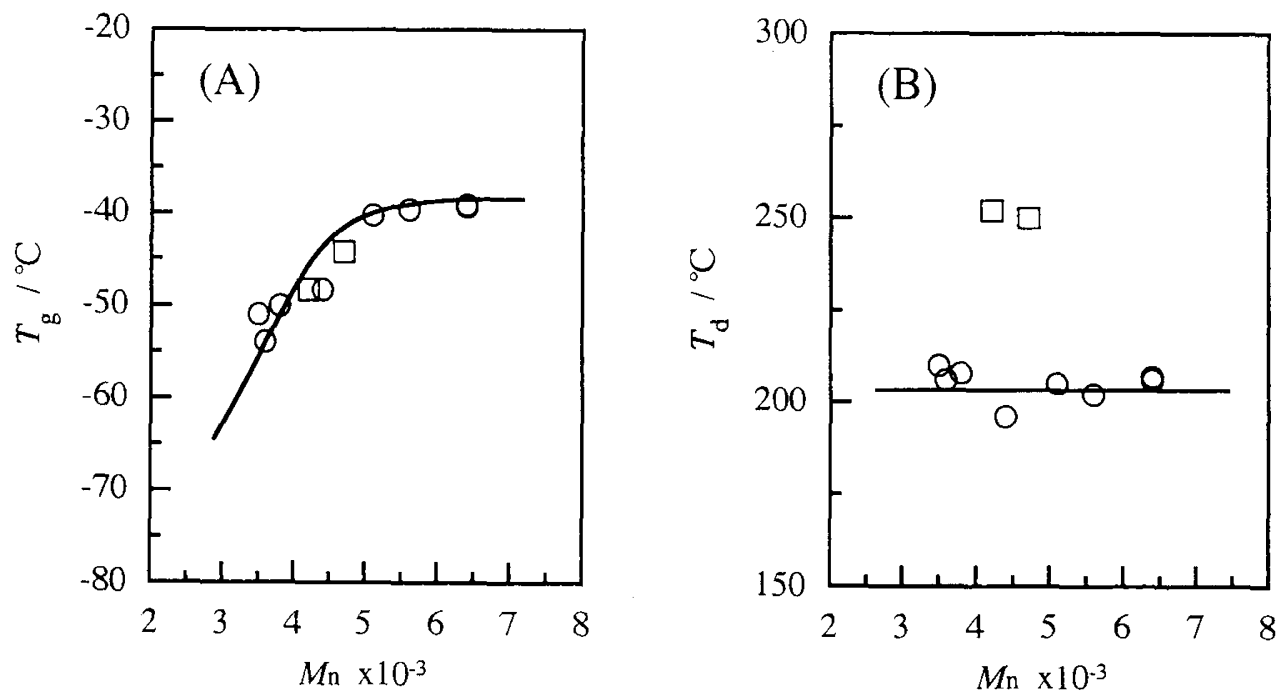

Figure 6. Relationships between $M_{n}$ and (A) $T_{\mathrm{g}}$, and (B) $T_{\mathrm{d}}$ for $(\bigcirc)$ poly(HEMS) and $(\square)$ poly(HMMS).

$T_{\mathrm{g}}$ and $T_{\mathrm{d}}$ of the poly(DTCA-EDA)s and poly(DTCAHDA)s were $-4.7--1.0^{\circ} \mathrm{C}$ and $146-182^{\circ} \mathrm{C}$, respectively, as shown in Table III. Figure 7 shows typical TG curves of the polymers. TG curves of poly(DTCA-HDA)s (runs 6 and 7 in Table III) exhibited similar tendency. However poly(DTCA-EDA)s (runs 3 and 4 in Table III) showed different TG curves.

Figure 8 depicts typical X-ray diffraction diagrams of poly(DTCA-EDA)s and poly(DTCA-HDA)s. The results indicate that the polymers are in amorphous and crystal states. Crystallinity was determined from area of crystalline and amorphous region in X-ray diffraction diagrams, as shown in Table III. And that of poly(DTCAHDA)s (runs 6 and 7 in Table III) was similar, 25.0\% and $26.7 \%$, but different for poly(DTCA-EDA)s (runs 3 and 4 in Table III), $49.3 \%$ and $28.7 \%$, respectively. It is difficult to clearly explain the reason, but theses results may be attributed to different molecular weights and/or structures of polymer end groups (Table III and Figure $5)$.

\section{CONCLUSION}

Three new monomers containing sulfur, HEMS, HMMS, and DTCA were synthesized from 3-MPA. The polycondensations of HEMS and HMMS were carried

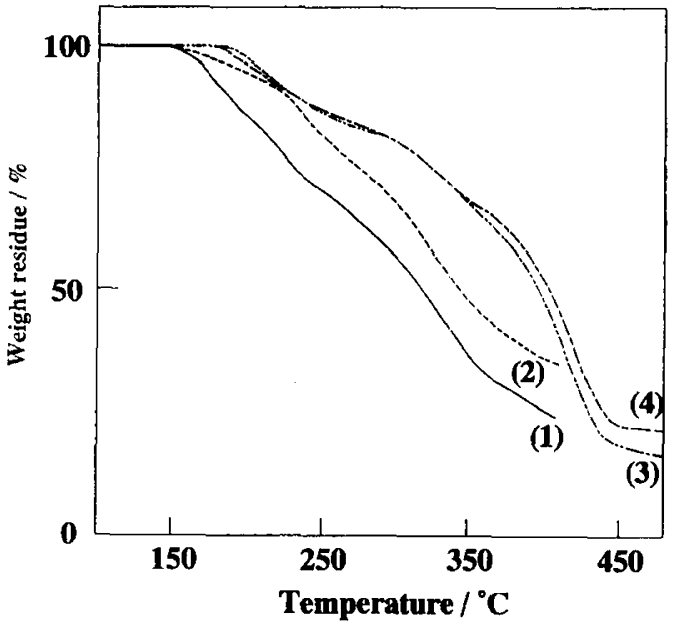

Figure 7. Typical TG curves of poly(DTCA-EDA) and poly(DTCA-HDA); (1) run 3, (2) run 4, (3) run 6, and (4) run 7 in Table III.

out with several metal acetates as catalysts to obtain the corresponding polythioethers with $M_{n}$ of up to $6.4 \times 10^{3}$, $T_{\mathrm{g}}$ of $-39--54^{\circ} \mathrm{C}$ and $T_{\mathrm{d}}$ of $196-252^{\circ} \mathrm{C}$. The radical polymerizations of DTCA were performed in bulk at 110 ${ }^{\circ} \mathrm{C}$ to form polymers having allyl groups in the side chain 


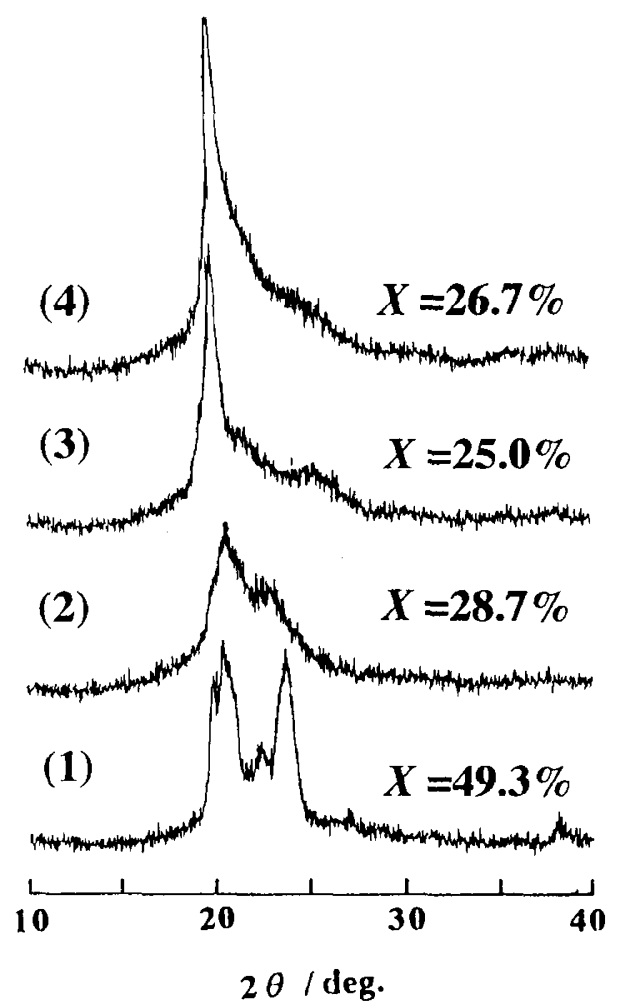

Figure 8. Typical XRD diagrams of poly(DTCA-EDA) and poly(DTCA-HDA); (1) run $3,(2)$ run 4 , (3) run 6 , and (4) run 7 in Table III. with $M_{n}$ of up to $2.7 \times 10^{3}$. The polycondensations of DTCA with EDA and HDA were accomplished to obtain the corresponding polymers with $T_{\mathrm{g}}$ of $-5--1{ }^{\circ} \mathrm{C}, T_{\mathrm{d}}$ of $146-182^{\circ} \mathrm{C}$ and crystallinity of $25-49 \%$.

Acknowledgments. We are thankful to Dr. K. Katoh in Nippon Oil \& Fats Co., Ltd. for supplying the 3-MPA and M3-MP.

\section{REFERENCES}

1. Y. Chujo, T. Shishino, Y. Tsukahara, and Y. Yamashita, Polym. J., 17, 133 (1985).

2. K. Ishihara, T. Tsuji, Y. Saka, and N. Nakabayashi, J. Polym. Sci., Polym. Chem., 32, 859 (1994).

3. K. Kuwano, T. Nishiyama, K. Nagata, and M. Nagasawa, Kobunshi Ronbunshu, 53, 85 (1996).

4. K. Kuwano, M. Nagasawa, H. Hibino, M. Tsuchimori, and S. Hyodo, Kobunshi Ronbunshu, 53, 159 (1996).

5. K. Kuwano, K. Nagata, M. Nagasawa, and H. Hibino, Kobunshi Ronbunshu, 53, 165 (1996).

6. A. Lezzi, S. Cobianco, and A. Roggero, J. Polym. Sci., Polym. Chem., 32, 1887 (1994).

7. M. A. R. Moraes, A. C. F. Moreira, R. V. Barbosa, and B. G. Soares, Macromolecules, 29, 416 (1996).

8. G. F. Meijs, T. C. Morton, and E. Rizzardo, Macromolecules, 24, 3689 (1991).

9. Y. K. Lee, H. Tsutsumi, T. Oishi, and T. Kato, Koubunshi Ronbunshu, 55, 49 (1998).

10. Y. K. Lee, K. Onimura, H. Tsutsumi, and T. Oishi, J. Polym. Sci., Polym. Chem., 37, 3871 (1999).

11. G. Odian, in "Prince of Polymerization", 3rd ed, John Wiley \& Sons, Inc., New York, N.Y., 1991, p 86. 